\title{
A COVID-19 EM GUINÉ-BISSAU: conjuntura econômica, social e política do país e a garantia dos direitos sociais
}

\author{
Leodinilde Pinto Caetano ${ }^{1}$ \\ Renata Lima Oliveira ${ }^{2}$ \\ Tino Tamba ${ }^{3}$ \\ Peti Mama Gomes ${ }^{4}$ \\ Farã Vaz ${ }^{5}$ \\ Ivanilson Monteiro ${ }^{6}$ \\ Bas'Ilele Malomalo $^{7}$
}

\begin{abstract}
Resumo
Com o avanço da COVID-19 no mundo, faz-se necessário refletir como a as distintas realidades influem sobre os processos de avanço e contenção dos impactos gerados a partir da pandemia. A Guiné-Bissau, sendo um país que vem registrando desde 1980 cíclicos golpes militares, tornou- se um país vulnerável em todas as vertentes. A vulnerabilidade do país é tanta que não se consegue fazer uma reforma estrutural no aparelho de Estado desde a sua independência do jugo português em 1973; desta forma esta República Democrática é dependente economicamente dos seus parceiros internacionais, até para execução do seu orçamento geral do Estado. Tendo a castanha-de-caju como o principal e quase único produto que movimenta a economia, o país viu as necessidades e as demandas da população se agravarem com a chegada
\end{abstract}

1 Graduada em Agronomia pela Universidade da Integração Internacional da Lusofonia Afro-Brasileira (UNILAB), mestranda em Desenvolvimento Territorial pela UNESP e bolsista Centro de Ciência e Tecnologia para Soberania e Segurança Alimentar e Nutricional da UNESP (INTERSSAN). Endereço eletrônico: lleopica@gmil.com, Orcid 0000-0002-9730-1656.

${ }^{2}$ Graduada em Agronomia pela Universidade da Integração Internacional da Lusofonia Afro-Brasileira UNILAB, mestranda em Desenvolvimento territorial pela UNESP e Bolsista INTERSSAN. Endereço eletrônico: renatalimapacoti@hotmail.com, Orcid 0000-0001-7048-0941.

${ }^{3}$ Bacharel em ciências Humanas, Bacharel em Teologia, licenciado em História, especializando em ciência Política e mestrando em interdisciplinar em Humanidades-UNILAB. Bolsista da FUNCAP. Endereço eletrônico: tino.tamba@yahoo.com.br, Orcid 0000-0001-5645-590X.

${ }^{4}$ Mestra em Antropologia pela Universidade Federal do Ceará (UFC) e Universidade da Integração Internacional da Lusofonia Afro-Brasileira (UNILAB). Doutoranda em Antropologia Social no Programa de Pós-Graduação em Antropologia (PPGA) da Universidade Federal do Pará (UFPA) e Bolsista da Coordenação de Aperfeiçoamento de Pessoal de Nível Superior - Brasil (CAPES). Endereço eletrônico: gomespetimama@gmail.com. Orcid 00000002-0414-8438.

${ }^{5}$ Graduado em Sociologia, Especialização em gestão pública Municipal e Mestre do programa Interdisciplinar em Humanidades pelo IHL/UNILAB, pesquisador do Grupo de pesquisa África-Brasil: Produção de conhecimento, Sociedade civil, Desenvolvimento e Cidadania Global/UNILAB/CNpq e integrante do MU-CONSAN/UNILAB. Email: vaz.fara@yahoo.com.br, Orcid 0000-0003-1733-697X.

${ }^{6}$ Bacharel em Ciências Humanas pela UNILAB, Licenciado em Sociologia, especialista em gestão hídricos ambientais e energética e mestrando em Medicina e Sociologia do abuso de drogas, Psicobiologia. Endereço eletrônico: pucomonteiro@gmail.com Orcid 0000-0003-3300-4043.

7 Doutor em Sociologia pela Universidade Estadual Paulista Júlio Mesquita/UNESP (2010), é docente de graduação nos cursos das Relações Internacionais, Ciências sociais e Mestrado Interdisciplinar em Humanidades (MIH) do Instituto de Humanidades e Letras (IHL) da (UNILAB), coordenador do Grupo de Pesquisa ÁfricaBrasil, pós-doutorando e bolsista INTERSSAN.. Endereço eletrônico: basilele@unilab.edu.br Orcid 0000-00027889-3385 
do novo coronavírus, tendo assim o aumento nas despesas das famílias em adquirirem produtos alimentares e de higiene para o enfrentamento da doença, face a debilidade económica dos seus cidadãos. O presente artigo tem por objetivo analisar os processos sociopolíticos que influem sobre o manejo da pandemia em Guiné Bissau. Tem como metodologia de trabalho, revisão de literaturas obtidas por meio de revistas cientificas e portais. Observou-se no percurso de desenvolvimento do trabalho e da pandemia, a necessidade da formação de novos quadros profissionais e maior investimento em estrutura, tanto econômica como de saúde, para que possam ser gerenciados momentos de crise como o enfrentado. O que só será possível por meio do alinhamento entre estado e sociedade civil em torno de um projeto de desenvolvimento participativo e solidário.

Palavras-chave: COVID-19; Guiné-Bissau; segurança alimentar; vulnerabilidade social

\section{Introdução}

Com longos períodos de instabilidade política que persistem até os dias atuais, Guiné Bissau enfrenta fragilidades que influem sobre a estruturação da sociedade e a soberania da nação. Mesmo depois de várias tentativas de reformas políticas, se instalou uma profunda dependência de instituições para além das fronteiras. Os países vizinhos acabam por, em parte, ditar como as políticas são direcionadas na nação. Obviamente, setores como ciência e tecnologia, são um dos mais atingidos, durante as crises, visto a precariedade de acesso a tecnologias avançadas, ou mesmo apropriadas à realidade do país.

Pensar essa construção histórica do cenário nacional, nesse momento é de fundamental importância, visto que o coronavírus é um desafio até para países considerados de primeiro mundo, que reúnem a posse da tecnologia necessária ao seu enfrentamento. Ao chegar em Guiné Bissau ele causa, para além dos impactos na saúde da população, uma profunda instabilidade institucional, com impactos diretos sobre os cidadãos. Questões recorrentes, como o acesso a saúde, ao alimento, que já são naturalmente parte das preocupações da população em tempos normais, assumem novas dimensões, o mesmo ocorre com a dependência externa.

Em termos práticos, a COVID-19 é uma doença respiratória causada pelo vírus SARSCoV-2 que pode progredir para síndrome respiratória aguda grave, com necessidade de internação e respiração artificial, podendo levar à morte. Essa emergente ameaça à saúde global atingiu o mundo inteiro. Segundo Monié (2020), os primeiros dados oficiais dos contaminados na África subsaariana foram registrados e divulgados nas metrópoles de Lagos em 27 de fevereiro de 2020 e Dakar 03 de março de 2020. Na Guiné-Bissau os primeiros casos foram registados no dia 25 de março de 2020. Face a essa doença, o país decretou estado de emergência no dia 27 de março de 2020. O Estado de emergência, decretado pelas autoridades, determina, medidas e protocolos preventivos e médicos para fazer face à pandemia, e traz 
pontos importantes como: restrição de circulação da população, confinamento e distanciamento social.

No último acesso de dados que se teve, a Guiné-Bissau está atualmente com 1.460 casos confirmados, 253 recuperados e 15 mortes (AGÊNCIA LUSA, 2020). Nessa evolução da curva de contágio, também evoluíram as disputas internas, seja pelo controle da crise sanitária, seja pela 'tomada' de poder. Em parte, tais disputas são positivas, quando consideramos que elas aceleram alguns processos e permitem, em certa medida, a regulação dos poderes. Mas também, em determinados momentos distanciam os olhares do centro da questão: a segurança social em meio a pandemia.

Uma dessas questões que envolveram calorosos discursos, políticos e científicos, se referiu ao momento em que o país adquiriu o chá de prevenção e cura dos sintomas da COVID19 produzido em República de Madagáscar (COVID-19..., 2020). Houve uma grande desconfiança no meio acadêmico guineense, porque este chá ainda precisa de comprovações científicas, o que impulsiona o questionamento sobre o porquê apostar em um composto que não apresenta efetividades científicas.

Frente aos últimos acontecimentos, o objetivo deste artigo é desenvolver uma análise crítica sobre a chegada da COVID-19 em Guiné-Bissau, diante da atual conjuntura política, social e econômica do país. Este trabalho propõe-se a realizar um relato conjuntural, por tratarse de um tema de interesse imediato, utilizando como ponto de partida informações disponíveis sobre o enfrentamento da COVID-19 em Guiné-Bissau, no intervalo de dois meses a partir do decreto de estado de emergência pelo governo daquele país. Seguindo as indicações de Gil (1996) em produzir o conhecimento a partir de textos sistematizados e publicados em periódicos especializados, livros e/ou trabalho de conclusão de curso. Adicionalmente, para registrar informações mais atualizados recorreu-se a dados que foram registrados, como exemplo em jornais impressos ou eletrônicos, arquivos, sites e registros audiovisuais.

\section{Contexto histórico e político de Guiné-Bissau}

O território que é conhecido hoje como República da Guiné-Bissau foi ex-colônia portuguesa, onde o seu povo foi escravizado e discriminado pelos portugueses. Esses colonizadores chegaram a essa Região da Costa Ocidental do continente africano em 1446. O país tem limitação fronteiriça com dois países da colônia francesa, Senegal ao Norte do país e Guiné-Conakry ao Sul. A sua superfície total é de $36.125 \mathrm{~km}^{2}$, e administrativamente, o país 
está dividido em oito Regiões, nomeadamente: Gabú, Bafatá, Oio, Tombali, Quinara, Biombo, Cacheu e Bissau.

No dia 23 de janeiro do ano de 1963, desencadeou-se a guerra da Libertação Nacional, liderada pelo Partido Africano da Independência de Guiné Bissau e Cabo Verde (PAIGC). A guerra tinha como intuito libertar toda população do território guineense que estava sob jugo colonial português. A guerra teve fim no dia 24 de setembro de 1973, com a independência conquistada, pelos combatentes da libertação da pátria guineense. Porém, essa conquista não foi reconhecida nessa data por Portugal, e isso só ocorreu em 10 de setembro de 1974, originando assim uma nova fase da história política da nação africana (CATEIA et al., 2018).

A Guiné-Bissau é um país em via de desenvolvimento, ou seja, ainda não tem economia consolidada, de modo que não consegue manter o seu orçamento geral do Estado com os recursos internos, e nem consegue financiar a realização das suas eleições. Para tanto, o país conta com apoio financeiro das organizações internacionais. Esta dependência econômica tornou-se mais visível na década de 80, quando o então presidente da República João Bernardo Viera (Nino), estava comandando a nação guineense. A crise, que assolou o país nessa década, levou o presidente da República a solicitar apoio do Fundo Monetário Internacional e do Banco Mundial, com objetivo de combatê-la. Além do mais, destaca-se que essa crise foi provocada pelo golpe de Estado que ocorreu no país, em 1980 (CATEIA et al., 2018).

No pós-golpe, para que o país recebesse a ajuda dessas organizações, teria que cumprir com as exigências impostas por esses parceiros. Entre elas, fazer as alterações constitucionais permitindo a passagem do partido único para o regime multipartidarismo, e reconhecimento da liberdade de cidadãos de professar a fé. A Guiné-Bissau passou por outros novos golpes militares em que o último foi em 2012, o que transparece uma sucessiva instabilidade política no país, e reflete diretamente no elevado nível de pobreza no seio da população guineense. De acordo com Nhanca (2013), essas crises políticas são fatores que causam o aumento da pobreza à população. Também afirma que:

A Guiné-Bissau carece de recursos próprios para financiar os principais programas de investimentos públicos, particularmente a infraestrutura estradas, aeroportos, portos, hospitais, pontes, etc., assim como o pagamento de salários, dívida externa, dentre outros. Em 2003, cerca de 97,9\% dos recursos financeiros foram contraídos no exterior a fim de equilibrar o déficit do orçamento público [...]. (NHANCA, 2013, p. 48). 
As sucessivas instabilidades influenciam bastante a dependência do país aos apoios externos para que se possa manter as suas despesas ao nível das instituições do Estado (SOUZA, 2012; SANTOS, 2019). Para compreender melhor sobre essa situação da crise política e militar no país, destaca-se que depois da instalação da democracia, nenhum Primeiro Ministro nomeado pelo presidente da República, com base dos resultados eleitorais, terminou o seu mandato como determinado por lei, que são de 4 anos.

A origem da instabilidade política na República da Guiné-Bissau pode ser resumida na disputa de controlar fontes de riquezas que se concentram nas instituições estatais. Sendo assim, perder poder em Guiné-Bissau significa sair do sistema, e sair do sistema é desligar-se das fontes de recursos. Como infere Costa (2019):

As constantes instabilidades políticas que o país conhece constituem um dos obstáculos na construção de políticas públicas efetivas, obtenção de condições propícias para produção e comercialização, bem como no aperfeiçoamento da democracia e estado de direito (SUCUMA, 2012, p. 111).

\section{Realidade Econômica do País e Segurança Alimentar e Nutricional}

Segundo os dados disponibilizados pelo banco africano de desenvolvimento, em 2020 a Guiné-Bissau é considerado como um dos países mais pobres do mundo, cerca de $67 \%$ de sua população vive em pobreza, 33\% em pobreza extrema; as desigualdades são elevadas, o desemprego é de $11,6 \%$ e os trabalhadores informais representam problemas estruturais. O país possui uma população vulnerável com dificuldades (NHANCA, 2013), com o novo corona vírus torna-se ainda mais perceptível as dificuldades em acessar itens de higiene básica, o que dificulta, por exemplo, a promoção de uma campanha de lavagem de mãos, assim como ocorre em grande parte da população brasileira (PECI, 2020).

Como uma forma de superação da pandemia em meio a fragilidades existentes em diversas realidades semelhantes a de Guiné Bissau, todos os campos da ciência se viram estimulados a se dedicarem às reflexões sobre os mecanismos para enfrentar a doença, apesar das circunstâncias exigirem muitas adaptações por parte dos países periféricos que, em maioria, detêm poucos recursos para a promoção de centros de pesquisa.

Quando se debate a COVID-19 e seus impactos, torna-se explícita que, essa crise sanitária mundial vem causando problemas sociais, o que é só um agravo de problemas já existentes como a pobreza, desigualdade social, econômica e sanitária. Como exemplo, a Organização Mundial de Saúde (2020) explica que os dados resultantes da ampliação de diagnóstico e detecção no ano 2018 de qual doença do HIV, apontam uma diminuição do 
número de pessoas contaminadas devido ao fato de existirem pessoas já tratadas. Os países localizados, no que se chama de espaço Sul, são polos da doença, onde temos: Índia com mais de 2,6 milhões de caso China com 866 mil, Indonésia, com 845 mil, Paquistão soma 562 mil, Filipinas, com 591 mil, Nigéria, com 429 mil e África do Sul com 301 mil. Na região conhecida por países que possuem Língua Oficial Portuguesa, as incidências de HIV manifestam-se em Moçambique com 162 mil casos, Angola com 109 mil casos e Brasil segue somando 95 mil. A Guiné-Bissau marca o número de 6,8 mil casos, Timor Leste 6,3 mil, Portugal 2,4 mil, São Tomé e Príncipe 260 e Cabo-Verde 250 casos, aponta a OMS, no seu relatório de 2019.

O ministro das finanças da Guiné-Bissau, em entrevista concedida à agência de notícias, DW África, no dia 25 de março de 2020, disse que a economia do país passará pela quebra de 50\% das receitas fiscais (DEUTSCHE WELLE, 2020a). A comercialização da castanha de caju, como um dos maiores alicerces do PIB iria decrescer, fato que reflete sobre até $80 \%$ da população, devido também a outros fatores e principalmente ao baixo valor de compra deste produto no mercado internacional. A castanha, segundo o ministro, ainda não tem contrato de compradores consolidados, em razão da pandemia e fechamento de fábricas de países como China, Índia e do Vietnam. Explica que, em geral os países da África Ocidental que produzem a castanha, como Costa de Marfim, Senegal, a própria Guiné-Bissau, o Benim e a Nigéria, estão ainda com estoques armazenados para comercializar, e esse fato terá impacto muito negativo sobre outros setores da economia.

Neste contexto, conforme o World Bank (2020a), o país ainda enfrenta vários obstáculos no que diz respeito ao acesso aos serviços de saúde, aos mercados de produtos agrícolas e pesqueiros que, constituem um entrave para a cobertura nacional. Entre esses obstáculos destacam-se: escassez de infraestrutura sanitária, insuficiência de recursos humanos, falta de equipamentos, maior demanda, dificuldade de pagamento dos usuários pelos serviços prestados, sistemas de informação de saúde não operacionais, atitude dos profissionais e características dos serviços de saúde.

Embaló (2008), em pesquisa sobre a questão da Insegurança Alimentar (ISAN), na zona leste do país, percebeu que, nesta região, o setor agrário é fortemente marcado pelas incertezas meteorológicas, ondulação de variabilidade da precipitação, alterações do padrão do cultivo, emigração de jovens para cidade, tendo sido esses fatores determinantes da ISAN na GuinéBissau.

Para Bayan (2010), a Insegurança Alimentar, nos contextos de zonas rurais, lideradas pelo poder tradicional, depende de um conjunto de esforços da comunidade/tabancas. Isso em 
razão da ausência de políticas de Estado em fazer frente ao fenômeno. $\mathrm{O}$ autor explica que as sociedades tradicionais, no contexto da Guiné-Bissau, procuram adaptar-se e encontrar novas estratégias para combater a ISAN sem forçar a alteração à vida endógena para os modos de produção que geram lucro.

O Escritório da ONU para Assuntos Humanitários (OVHA) fez a previsão que aponta que 9,6 milhões de pessoas enfrentam uma grave situação de insegurança alimentar, que provinha de catástrofes ambientais na África Austral. Na mesma ótica, a Nações Unidas Brasil (2020), sinaliza que, a fome na África vinha crescendo, em 2017 e, indica que 257 milhões de pessoas, que correspondem a $20 \%$ do continente africano e, desse grupo, 237 milhões estão localizada na região da África Subsaariana. Portanto, a ONU por meio da FAO já alertava que, a atual crise pode tornar-se fator de aumento de fome, atingindo cerca de 265 milhões de pessoas (NAÇÕES UNIDAS BRASIL, 2020).

Segundo a Organização das Nações Unidas (2020) nem um trabalho feito em parceria com o governo brasileiro, a Guiné-Bissau já vinha demonstrando sinais de melhoria face a insegurança alimentar e nutricional no ano 2018. Para esta organização, o sistema de monitoramento nutricional do país indica que a insegurança alimentar entre população rural estava acima de 30,6\% no ano 2016 e de $20 \%$ em outubro de 2017 . A razão determinante da queda tinha a ver com o aumento de preço da castanha-de-caju, conhecido como o produto que domina a agricultura camponesa guineense e que gera mais commoditie.

\section{Enfrentamento da COVID-19 pelo Governo e Sociedade Civil}

Com a chegada da COVID-19 na Guiné-Bissau e, apesar do país se encontrar na condição de troca de poderes com a posse do novo presidente da República, a sociedade guineense assumiu, de forma expressiva e com alta solidariedade, a decretação de estado de emergência no dia 27 de março de 2020. O enfrentamento da COVID-19 possibilitou o mais amplo engajamento, não só a nível de Estado/governo, mas igualmente das organizações da sociedade civil e a diáspora do país.

As medidas de isolamento, tidas como estratégia face a acelerada infeção de coronavírus nos demais países, não deixaram de ser um fato na Guiné-Bissau. Essas exigem também as práticas de higienização, e distanciamento social. Com isso, em 14 de junho, a plataforma Afrique CDC (AFRICAN UNION, 2020) da União Africana, através dos seus dados fez perceber a tendência de aumento de casos da doença no continente. 
Depois de decretado o estado de emergência, pode-se perceber que, de um lado, em resposta desta medida tornou-se mais evidente a precariedade das infraestruturas hospitalares, a necessidade de treinamento de novos profissionais de saúde e os demais profissionais ligados ao enfrentamento dos adoecimentos, os modos violentos de abordagem policial etc. Por outro lado, as famílias e mulheres do setor da economia rural e da informalidade, demonstraram impossibilidade de adotar todas as medidas exigidas pelo Estado, (COMÉRCIO..., 2020). Logo, nas primeiras instâncias, a população guineense começou a experimentar as recomendações do ministério da Saúde.

Segundo Garcia e Duarte (2020), práticas como medidas individuais (lavagem das mãos, uso de máscaras, distanciamento social) ambiental (limpeza rotineira de ambientes, superfícies e objetos) e comunitárias (restrição do funcionamento de escolas, universidades, locais de convívio comunitário, transporte público e outros locais onde há aglomeração de pessoas (eventos tradicionais, religiosos, esportivos, teatros, cinemas e estabelecimentos comerciais) são utilizadas como principais estratégias de prevenção da propagação da doença. As medidas de isolamento têm sido as mais desafiadoras no contexto da Guiné-Bissau, resultante de enfrentamento e resistência policial e a violência desta para com a população (Agência Lusa, 2020), a vulnerabilidade socioeconômica de famílias e principalmente das mulheres vendedoras.

Diante de uma pandemia, nasce a necessidade de novas reflexões, experiências, práticas sociais para prevenção. Nesta ótica, o governo da Guiné-Bissau busca reforçar recursos econômicos nos órgãos da comunicação social, públicas, comunitárias, e, privados (TVs, rádios), reabertura do serviço alimentar do hospital nacional, prolongamento de estado de emergência, fornecimento de alimentos a famílias em situação de vulnerabilidade em todas as regiões, incluindo inauguração da sede de combate à epidemia, formação da Alto Comissariado de Luta contra COVID-19 e, fornecimento de 5 mil máscaras.

Antes de reverberar sobre as estratégias utilizadas pelo ministério da saúde da GuinéBissau, face ao enfrentamento da COVID-19, é importante explanar o seguinte: na atual conjuntura da saúde pública global, com a pandemia, causada pelo novo coronavírus, é consensual que as medidas de saúde são essenciais para adiar a transmissão e a propagação do vírus, assim como mitigar seus impactos. Posto isso, considerando a falta, atualmente, de vacinas ou medicamentos específicos que demonstram eficácia para a doença (COVID-19), as medidas não farmacológicas são estratégias adicionais e fundamentais para a supressão e mitigação da força da doença. 
No entanto, dentre essas medidas, a que já mostrou o maior impacto é o isolamento social, a dita quarentena. O distanciamento físico-social protege a população de um perigo invisível, e mesmo em pessoas que já contraíram o vírus, na sua fase inicial de progressão, o desenvolvimento dos sintomas da doença não se manifestam, na maioria dos casos. Baseado no exposto, a execução de políticas de distanciamento horizontal já mostrou que beneficia a sociedade. Ao reduzir o contato físico e social entre os indivíduos, haverá a redução do número dos infectados em determinado período, em função da menor transmissão da doença entre a população.

$\mathrm{Na}$ Guiné-Bissau, uma das medidas tomadas para enfrentar o novo coronavírus foi a decretação do estado de emergência pelas as autoridades do país, no dia 27 de março de 2020 . Para justificar o seu decreto, o autoproclamado presidente da república, Umaro Sissoco Embaló, diz que a medida foi de caráter "excepcional" que visa "salvaguardar" bens essenciais, valores e princípios fundamentais:

A Constituição da República permite que, em situações como esta que estamos a viver, de calamidade pública, sejam suspensos alguns direitos, liberdades e garantias dos cidadãos, através da declaração do estado de emergência, uma medida excecional com vista a salvaguardar bens essenciais, valores e princípios fundamentais, previstos na Constituição. (DEUTSCHE WELLE, 2020b).

Diante do exposto, o decreto passa pela necessidade do cumprimento dos objetivos da base jurídica e constitucional. As implicações jurídicas que restringem os direitos de liberdades de ir e vir e demais outras garantias, que o governo vem tomando, através do seu plano de abrandamento da doença, o estado de emergência, deliberado pelo Conselho de Ministros (CM), está alinhada à necessidade de criação de um instrumento no âmbito legal que leva em conta a realidade guineense no que diz respeito ao enfrentamento da pandemia.

Dentre várias implicações, resultantes do estado de emergência, temos a criação de unidades sanitárias de campanha; uma em Bissau, capital do país, no Hospital Nacional Simão Mendes, e outro em Hospital de Cumura comandado pelas autoridades religiosas da Região de Biombo no Norte do País. No mesmo intento, podemos referenciar também a "ajuda" recebida da Organização Mundial da Saúde (OMS), no que concerne aos materiais de testagem e da proteção médica; assim como, a ajuda recebida, no âmbito interno do continente africano, por meio da cooperação estabelecida entre a Guiné-Bissau e Madagascar. Referimos a solicitação do chá, Covid Organics feita pelo governo guineense à República de Madagáscar.

Outra medida de enfrentamento que merece a nossa atenção e reflexão foi o encerramento, no dia 13 de abril de 2020, pelas autoridades sanitárias do país, do maior e 
melhor centro médico hospitalar privado da Guiné-Bissau, a clínica Madrugada (COVID-19..., 2020). Tal fato se deu, segundo o jornal África 21 digital (2020), devido ao falecimento de uma senhora por motivos desconhecidos. E para conter a suposta contaminação e propagação do vírus resolveu-se interditar o referido centro, deixando milhares de pessoas, a própria sorte, no que concerne aos serviços de urgência e emergência prestados pela clínica. Por último, foi criado uma comissão interministerial de acompanhamento dos pacientes com COVID-19. Ou seja, são as pessoas que estão na linha de frente nos cuidados e gestão dos casos. Sem esquecer da solidariedade da sociedade civil, das organizações locais, grupos de mulheres, movimentos e associações locais e nacionais. Destaca-se, por exemplo, a organização dos médicos sem fronteiras em parceria com a OMS, que têm recrutado profissionais da área de saúde para trabalhar na linha de frente em algumas partes da Guiné e não apenas na capital do país, onde se encontram mais casos de infectados. Os movimentos e associações de mulheres tem doado também materiais de higiene e cestas básicas para população mais carenciadas.

\section{Problemas sociais e políticos levantados pela COVID-19}

Segundo Nunes (2020), ao considerar a vulnerabilidade da população inerente a modelos econômicos vigentes, a exemplo o neoliberalismo, reflete acerca de como a pandemia se instala e medidas que resultam a partir disso, como também de seus impactos, econômicos, sociais e culturais, estabelecendo a relação: economia e vulnerabilidade frente a pandemia de COVID-19.

É importante pensar a atual crise da saúde, por meio de políticas que sejam direcionadas, também, às camadas invisíveis, visto que elas, em grande parte, apresentam maior carga de doenças pré-existentes que precisam ser consideradas no enfrentamento da COVID-19 (CALMON, 2020). É urgente pensar nas pessoas em situação de vulnerabilidade social, não como uma problemática no enfrentamento da COVID-19, mas, como peça chave para a baixa dos índices de circulação do vírus, destinando medidas de tratamentos dignas, e também adaptar medidas para barrar o desemprego, a fome e a crescente dificuldade ao acesso a atendimentos em casos de agravos de saúde, porque na verdade estas situações contribuem na exposições dos vulneráveis a doença.

Como infere Calmon (2020), sobre a COVID-19 "não chega a ser uma doença democrática, como afirmam alguns, visto que as condições de prevenção e cuidado se impõe de formas diferentes a segmentos sociais distintos, assim como o potencial de letalidade vírus" (CALMON, 2020, p. 131). O autor evidência a necessidade de medidas especificas para 
camadas sociais que em seu cotidiano tem rotinas distintas e que influem sobre o adoecimento da população. Como conclui Calmon (2020), a população negra, historicamente, passa por processos de negação de seus direitos e no momento de uma pandemia, é uma das camadas sociais que já vem de processos excludentes. Pensar o enfrentamento desses abismos sociais é tão urgente como pensar a solução para a COVID-19.

Em Guiné Bissau, pela condição do país, que se encaixa perfeitamente no perfil geral dos países mais pobres, é óbvio afirmar que o financiamento da ciência é escasso e quase inexistente. Segundo Gebregziabher e Hansen (2018), desde o ano 2012 tem sido destinado à saúde, valores que não ultrapassam os 9\% do Orçamento Geral de Estado (OGE). Segundo a Organização Mundial da Saúde (2020), a população guineense apresenta outros problemas de saúde como doenças cardiovasculares, tuberculose e câncer, esses são entraves a serem enfrentados, juntamente aos agravos ocasionados nos pacientes que adquirirem a COVID-19; para singularizar o caso guineense, existe ainda a constante instabilidade política vivida desde a década de 80 .

Em Bissau, conforme Darame (2020), verificaram-se muitas denúncias de repressão Policial contra os cidadãos, a força policial armada nos meados do mês de Março de 2020 (início da quarentena) abordou de forma brutal os cidadãos de Bissau (capital) que foram pegos a descumprirem o distanciamento e o isolamento social nos horários estipulados (livre circulação só das 7 às $12 \mathrm{~h}$ da manhã, de acordo com os quatro decretos presidenciais emitidos).

As denúncias dos citadinos de Bissau e da Liga dos Direitos Humanos, obrigou o Secretário de Estado da Ordem Pública, Mário Fambé, a pedir desculpas publicamente no dia 06 de abril 2020, o que impulsionou a mudança de estratégia dos policiais, onde optou-se em conduzir coercitivamente os que estão a descumprir o decreto para um estádio de futebol, onde são deixados livremente sem o cumprimento do distanciamento mínimo de $1 \mathrm{~m}$ entre as pessoas, e sem a exigência de se protegerem com máscaras. O cenário de capital Bissau reflete nas 8 capitais regionais, mas, não na zona rural desses locais. A zona rural guineense apresenta, e sempre apresentou, uma ausência de autoridade legal do país, deste modo, o combate ao Coronavírus não é o foco principal nessa zona, mas sim, a colheita e comercialização da castanha-de-caju que é o principal produto de exportação da Guiné e responsável por $80 \%$ do PIB.

Como uma lente de aumento, as características epidemiológicas da crise do novo coronavírus evidenciaram as carências sanitárias em Guiné-Bissau. O caso, por exemplo, de um sistema de saúde insuficiente, da falta de saneamento básico para a população, que contaria 
com abastecimento hídrico, coleta e tratamento de esgoto, moradias adequadas ao isolamento social, inexistentes. Os serviços públicos precários, a falta do capital (uma renda fixa) para grande parte da população, que não consegue manter a higienização básica, por conta do desabastecimento ou sub abastecimento de água potável nas oito regiões do país. Motivos pelos quais são vistos claros descumprimentos dos protocolos que reduzem o risco de contaminação, mesmo sabendo do colapso que pode haver no sistema de saúde, referimo-nos especificamente às fragilidades da infraestrutura no país que têm se acentuado ao longo das últimas décadas após abertura política, como foi sublinhado anteriormente.

\section{Considerações finais}

A Guiné-Bissau é um país com menos de 50 anos de independência, que apresenta desde várias fragilidades, estas se agravaram com a chegada da COVID- 19, evidenciando várias necessidades para um combate adequado, o que deixa o papel do estado em apoiar e proteger o povo muito contestável, devido as instabilidades vividas desde a sua independência, conquistada por meio de luta armada em 1973. Os guineenses possuem desde então um espirito desassossegado perante as incertezas provocadas pelos seus dirigentes, mas, que em todo caso, preferem andar com os seus próprios pés como dizia o Amilcar Cabral, pai fundador na nação, ou seja, não que gostem destas sucessivas instabilidades, mas sempre escolherão a liberdade. É valido refletir a cerca do papel das autoridades em investir na ciência e nos cientistas guineenses, para que esses possam fazer a ciência e aplicá-la a realidade do país, o que não vem ocorrendo, a necessidade da formação de quadros, a insuficiência de profissionais e estrutura ficou perceptível, e até agravou-se, na ocorrência da COVID-19, refletindo sobre o contexto social, com o aumento da vulnerabilidade. Por fim, vale a pena enfatizar que a sociedade civil é uma grande aposta para uma nova revolução contemporânea necessária no cenário político guineense, e também necessário enfatizar a necessidade do país de mais profissionais formados e meios de trabalho, que favoreçam o desenvolvimento social, construindo meios para o enfrentamento de emergências, como no caso da COVID-19

\section{Referências}

ÁFRICA 21 DIGITAL. Covid-19/Guiné-Bissau: autoridades encerram clínica em Bissau por suspeita de contaminação. São Paulo: CCA - Consultores de Comunicação Associados, 2020. Disponível em: https://africa21digital.com/2020/04/13/covid- 19-guine-bissau-autoridadesencerram-clinica-em-bissau-por-suspeita-de-contaminacao/. Acesso em: 13 jun. 2020. 
AFRICAN UNION. Africa CDC Dashboard. Addis Ababa: African Union, 2020. Disponível em: www.africacdc.org. Acesso em: 14 jun. 2020.

AGÊNCIA LUSA. Covid-19: ONG denuncia violência policial na Guiné-Bissau. Bonn: DW, 2020. Disponível em: https://www.dw.com/pt-002/covid-19-ong-denuncia-violência-policialna-guiné-bissau/a- 53463546. Acesso em: 12 jun. 2020.

BAYAN, L. M. T. L. R. Autoridades tradicionais, insegurança alimentar e gestão de recursos: um estudo de caso no Reino Felipe de Suzana (Guiné-Bissau). 2020. 116 f. Dissertação (Mestrado) - Escola de Sociologia e Ciências Públicas, ISCTE Instituto Universitário de Lisboa, Lisboa, 2010. Disponível em www: http://hdl.handle.net/10071/3900. Acesso em: 13 jun. 2020.

CALMON, T. V. L. As condições objetivas para o enfrentamento ao COVID- 19: abismo social brasileiro, o racismo, e as perspectivas de desenvolvimento social como determinantes. Nau Social, Salvador, v. 11, n. 20, p. 131, 2020. Disponível em:http://dx.doi.org/10.9771/ns.v11i20.36543. Acesso em: 14 jun. 2020.

CATEIA, C. et al. A mudança estrutural em Guiné-Bissau. TEC Textos Econ., Florianópolis, v. 21, n. 1, p. 97-124, 2018. Disponível: http://dx.doi.org/10.5007/21758085.2018v21n1p97.Pdf. Acesso em: 14 jun. 2020.

COMÉRCIO informal na Guiné-Bissau vai sofrer impacto imediato e pobreza pode aumentar, diz analista. Observador, Lisboa, 1 abr. 2020. Disponível em: https://www.google.com/amp/s/observador.pt/2020/04/01/comercio-informal-na-guinebissau- vai-sofrer-impacto-imediato-e-pobreza-pode-aumentar-diz-analista/amp/. Acesso em: 25 maio 2020.

COSTA, P. A. Instabilidade política na Guiné-Bissau: dimensões, causas e efeitos. 2019. Dissertação (Mestrado em Ciência Política) - Escola de Sociologia e Ciências Públicas, ISCTE Instituto Universitário de Lisboa, Lisboa, 2019.

COVID-19: Madagáscar oferece medicamentos de combate ao novo coronavírus para África ocidental. O Democrata, Bissau, 2 maio 2020. Disponível em: https://www.odemocratagb.com/?p=24643. Acesso em: 13 jun. 2020.

DARAME, B. Em meio a contencioso judicial, Sissoco toma "posse simbólica" como Presidente da Guiné-Bissau. Bonn: DW, 2020. Disponível em: https://www.dw.com/pt002/em-meio-a-contencioso-judicial-sissoco-toma-posse-simbólica- como-presidente-daguiné-bissau/a-52560557. Acesso em: 27 jul. 2020.

DEUTSCHE WELLE. COVID-19: Guiné-Bissau prevê quebra de até 50\% nas receitas fiscais. Bonn: DW, 2020a. Disponível em: https:/www.dw.com/pt-002/covid-19guin $\% \mathrm{C} 3 \% \mathrm{~A} 9$ - bissau-prev\%C3\%AA-quebra-de-at $\% \mathrm{C} 3 \% \mathrm{~A} 9-50$-nas-receitas-fiscais/a53167877. Acesso em: 11 jun. 2020.

DEUTSCHE WELLE. Covid-19: Sissoco Embaló declara estado de emergência na GuinéBissau, 2020b. Disponível em: https://www.dw.com/pt-002/covid-19-sissocoembal\%C3\%B3-declara-estado- de-emerg\%C3\%AAncia-na-guin\%C3\%A9-bissau/a52945653. Acessado no dia 13 de junho de 2020.

EMBALÓ, G. B. A vulnerabilidade da população às alterações agro-ecologicas. Estudo de caso no sector de pirada, região de Gabu, Guiné-Bissau. 2008. Dissertação (Mestrado em Economia Agrária e Sociologia Rural) - Instituto Superior de Agronomia, Universidade 
Tecnica de Lisboa, Lisboa, 2008. Disponível em:

http://oasisbr.ibict.br/vufind/Record/RCAP_4ce295827082c4749734d851e1a646a0. Acesso em: 14 jun. 2020.

GARCIA, L. P.; DUARTE, E. Intervenções não farmacológicas para o enfrentamento à epidemia da COVID-19 no Brasil. Epidemiol. Serv. Saúde, Brasília, v. 29, n. 2, p. e2020222, 2020. Disponível em: http://www.scielo.br/scielo.php?script=sci_arttext\&pid=S2237 96222020000200100\&lng=en\&nrm=iso. Acesso em: 21 jun. 2020.

GEBREGZIABHER, F. H.; HANSEN, K. Guinea-Bissau: public expenditure review. Seizing the moment - Managing public finance for development (English). Washington, D.C.: World Bank Group, 2018. Disponível em:

http://documents.worldbank.org/curated/en/258321560344202485/Seizing-the- MomentManaging-Public-Finance-for-Development. Acesso em: 14 jun. 2020.

GIL, A. C. Como elaborar projetos de pesquisa. São Paulo: Editora Atlas, 1996.

GOMES, R. Análise e interpretação de dados de pesquisa qualitativa. In: DESLANDES, S. F. Pesquisa social: teoria, método e criatividade. 31. ed. Petrópolis: Vozes, 2012. p. 79-107.

MONIÉ, F. A África subsaariana diante da pandemia de Coronavírus/COVID-19: difusão espacial, impactos e desafios. Esp. Econ: Rev. Bras. Geogr. Econ., Rio de Janeiro, v. 9, n. 18, p. 1-26, 2020. DOI 10.4000/espacoeconomia.13629.

NAÇÕES UNIDAS BRASIL. (FAO): 257 milhões de pessoas passam fome na África. Brasília, 2020. Disponível em: https://nacoesunidas.org/fao-257- milhoes-de-pessoas-passamfome-na-africa/. Acesso em: 11 jun. 2020.

NAÇÕES UNIDAS BRASIL. Guiné-Bissau: insegurança alimentar em zonas rurais cai 10\% em 2016-2017. Brasília, 2017. Disponível em: https://nacoesunidas.org/guine-bissauinseguranca-alimentar-em-zonas-rurais-cai-10-em-2016- 2017/. Acesso em: 12 jun. 2020.

NHANCA, V. J. L. Macroeconomia recente de Guiné-Bissau: perspectiva no contexto regional globalizado. 2013. 116 f. Dissertação (Mestrado em Economia) - Universidade Federal de Pernambuco - Campus do Agreste, Caruaru, 2013.

NUNES, J. A pandemia de COVID-19: securitização, crise neoliberal e a vulnerabilização global. Cad. Saúde Pública, Rio de Janeiro, v. 36, n. 5, p. e00063120, 2020. DOI 10.1590/0102-311x00063120.

ORGANIZAÇÃO MUNDIAL DA SAÚDE. África ultrapassa 200 mil infectados por pandemia e Guiné-Bissau pede drones. ONU News, Brasília, 11 jul. 2020. Disponível em: https://news.un.org/pt/story/2020/06/1716502. Acesso em: 14 jul. 2020.

PECI, A. Ações e estratégias COVID-19. RAP Rev. Adm. Pública, Rio de Janeiro, mar. 2020. Disponível em: https://blog.scielo.org/blog/2020/03/30/rap-acoes-e-estrategias-covid19/. Acesso em: 21 maio 2020.

SANTOS, M. C. R. Guiné-Bissau: da independência colonial à dependência da cooperação internacional para o desenvolvimento. Rio de Janeiro: Gramma, 2019.

SOUZA, J. S. Guiné-Bissau: a destruição de um país, desafios e reflexões para uma nova estratégia nacional. Coimbra: Panto4, 2012. 
SUCUMA, A. Breve histórico sobre a construção do Estado da Guiné-Bissau. Cad. Hist.

UFPE, Recife, 2012. Disponível em: file://C:/Users/Cafacsi\%C3\%A3/Downloads/11009959067-1-PB.pdf. Acesso em: 3 jun. 2020.

WORLD BANK. Health Nutrition Population Global Practice. Africa Region. Guinea

Bissau: qualitative assessment of demand side constraints to access maternal and child health services. Washington, DC: World Bank, 2020. Disponível em:

https://openknowledge.worldbank.org/handle/10986/32028. Acesso em: 1 jun. 2020

\title{
COVID-19 IN GUINEA-BISSAU: the country's economic, social and political situation and the guarantee of social rights
}

\begin{abstract}
With the advance of COVID-19 in the world, it is necessary to reflect on how the different realities influence the processes of advancement and containment of the impacts generated from the pandemic. Guinea-Bissau, being a country that has been recording military coups since 1980, has become a vulnerable country in all respects. The vulnerability of the country is so great that structural reform has not been possible in the state apparatus since its independence from the yoke Portuguese in 1973; in this way this Democratic Republic is economically dependent on its international partners even for the implementation of its general state budget. With cashew nuts as the main and almost only product that moves the economy, the country has seen the needs and demands of the population worsen with the arrival of the new coronavirus, thus having the increase in the expenses of families in acquiring food and hygiene products to cope with the disease, in view of the economic weakness of its citizens. This article aims to analyze the sociopolitical processes that influence the management of the pandemic in Guinea Bissau. Its work methodology is a review of literature obtained through scientific journals and portals. It was observed in this path the need for training of new professional staff and greater investment in the structure, both economic and health, so that we can manage moments of crisis as faced. This will only be possible through the alignment between state and civil society around a participatory and supportive development project.
\end{abstract}

Keywords: COVID-19; Guinea-Bissau; food security; social vulnerability

\section{COVID-19 EN GUINEA-BISSAU: la situación económica, social y política del país y la garantía de los derechos sociales}

\begin{abstract}
Resumen
Con el avance de COVID-19 en el mundo, es necesario reflexionar sobre cómo las diferentes realidades influyen en los procesos de avance y contención de los impactos generados por la pandemia. Guinea-Bissau, al ser un país que ha estado registrando golpes militares desde 1980, se ha convertido en un país vulnerable en todos los aspectos. La vulnerabilidad del país es tan grande que la reforma estructural no ha sido posible en el aparato estatal desde su independencia del yugo portugués en 1973; de esta manera esta República Democrática depende


económicamente de sus socios internacionales incluso para la ejecución de su presupuesto general del Estado. Con las nueces de anacardo como principal y casi único producto que mueve la economía, el país ha visto empeorar las necesidades y demandas de la población con la llegada del nuevo coronavirus, contando así con el aumento de los gastos de las familias en la adquisición de alimentos y productos de higiene para hacer frente a la enfermedad, en vista de la debilidad económica de sus ciudadanos. Este artículo tiene como objetivo analizar los procesos sociopolíticos que influyen en la gestión de la pandemia en Guinea Bissau. Su metodología de trabajo es una revisión de la literatura obtenida a través de revistas científicas y portales. En este camino se observó la necesidad de formación de nuevos profesionales y una mayor inversión en la estructura, tanto económica como sanitaria, para que podamos gestionar momentos de crisis como afrontados. Esto sólo será posible a través de la alineación entre el Estado y la sociedad civil en torno a un proyecto de desarrollo participativo y de apoyo.

Palabras clave: COVID-19; Guinea-Bissau; seguridad alimentaria; vulnerabilidad social 